\section{Facilitating the Impact Implementation Programme}

\author{
Sharon Markless and \\ David Streatfield
}

\section{The Authors}

Sharon Markless is a Senior Associate with Information Management Associates and part-time Lecturer, Institute for Learning and Teaching, King's College, London, where she is helping academic staff to develop as teachers. David Streatfield is Principal of Information Management Associates, a research, training and consultancy team working in the public sector and concentrating on education, health and libraries. Their book Evaluating the impact of your library service: the quest for evidence will be published by Facet later in 2005.

Email: Sharon.markless@blueyonder.co.uk; Streatfield@blueyonder.co.uk

\begin{abstract}
This paper describes the process model used in the Impact Implementation Programme and its origins in earlier research and development conducted in the schools, further education and public libraries domains. The choice of an action research methodology is discussed. The facilitation process undertaken through the first annual cycle of the Programme is described and various lessons learnt are reported. Conclusions are offered on the success of the Programme so far and on some factors likely to influence success if this model is adopted elsewhere.
\end{abstract}

\section{Origins of the process}

The process devised for the Impact

Implementation Programme had its roots in our earlier research on school, further education and public libraries. When we embarked on the Effective School Library national research project $^{1}$ we chose to define effectiveness in terms of supporting teaching and learning within the school. This decision led us directly into the area of evaluating the impact of services as well as into the substantial literature on educational evaluation ${ }^{2}$.

A similar focus during the Effective College Library ${ }^{3}$ project took us one step further. Since phase two of that project entailed college library teams working with us to evaluate a series of specific innovations, it was important that we all develop a common understanding of what impact evaluation was and how it could be tackled. This requirement led us to map out a process in the form of a training workshop, in which participants were helped through a series of stages within a common framework. The project then became an opportunity to gather evidence of impact for each innovation and at the same time to test the impact criteria and means of gathering evidence of success or otherwise ${ }^{4}$.

Shortly after concluding this project we were asked to conduct an evaluation (for the National Literacy Trust) of public library involvement in the National Year of Reading 5 . This led us to review all the annual library plans deposited that year by library services at the Department for Culture, Media and Sport. It soon became clear that, although most library services had engaged enthusiastically with the Year and were busy organising events to encourage reading for pleasure, most had baulked at offering any attempt to focus on the potential impact of these events. When we followed up with a national survey we found widespread confusion and uncertainty about the whole area of evaluating impact.

Partly as a result of our experience with the Year, we secured a further grant from the Library and Information Commission to explore practical issues of impact evaluation by working 
with various public library and schools library services management teams ${ }^{6}$. The resulting elaboration of the earlier process model developed for further education librarians, with accompanying support materials, was published as part of this project and is still available ${ }^{7}$. We were also asked to conduct a critical review of the Library and Information Commission's Value and Impact research programme ${ }^{8}$, which demonstrated that academic researchers, as well as library service managers, found it difficult to engage with the impact of library services.

In December 2002 we were invited to facilitate a UK national workshop for members of LIRG and SCONUL. This 24-hour event, Do libraries aid learning? Approaches and methods for measuring impact, was designed for university library managers and was held at Scarborough.

Both organisations were sufficiently convinced of the case for doing further work on service impact to commit to organising the programme of research and development that became the Impact Implementation Initiative. This Initiative is based on action research principles and uses a facilitated approach to supporting the key processes involved. It is designed as a process to encourage systematic exploration of the issues involved in gathering evidence of impact by staff of the participating university libraries.

\section{Action research}

Since the primary focus of the programme is on improving practice, with the development of theory and understanding as a secondary concern, an action research approach seemed appropriate. John Elliott ${ }^{9}$ defined action research as "the study of a social situation with a view to improving the quality of action within it"; a view broadly shared by most writers on the topic ${ }^{10}$. They also emphasise that action research offers possibilities for practical work that is also a form of learning for those involved. Two key aspects of action research are that it involves interventions into real situations and that the (intended and accidental) effects of the interventions form the main focus of the research.
Our starting point was that the best people to generate evidence about what is possible, as well as about which approaches work well and why, are the practitioners themselves. They should also be engaged in deciding how different approaches might be used by other busy practitioners and about the usefulness of the data generated in informing and developing practice. External researchers should be able to deploy a wider repertoire of methods to evaluate the impact of library services on teaching, learning and research. However, the transient nature of most external research interventions will not empower university library staff to continue to collect evidence and to learn about the issues over time - a key aim of the Initiative. Action research as a form of social research is not a detached, specialised, technical activity but one closely linked to reflective practice, designed to be undertaken by practitioners and to empower them. ${ }^{11}$

If action research is well designed and implemented, it also offers the possibility of generating data to support theorising, to develop understanding and to create new knowledge. ${ }^{12}$ Taking this extra step demands a rigorous, critical and systematic approach and makes heavy demands on participant researchers. Since the Impact Implementation Initiative is intended to address these larger issues, it seemed appropriate to use external facilitators to support the process.

\section{Facilitating the process}

The remainder of this paper will concentrate on the facilitation of the programme through its first annual cycle, leaving other contributors to report on the success or otherwise of the individual initiatives and the programme as a whole.

Since there appears to be growing interest in service impact and particularly enhanced interest in e-learning interventions in libraries and information services ${ }^{13}$, the model adopted for this programme is of potential wider relevance. Accordingly, we have set out here to describe the process through to the completion of the initial cycle in June 2004. 
The impact process model, which forms the basis of our training and drove the first phase of the Impact Implementation Initiative, starts with persuading managers to focus on what they are trying to achieve (expressed as specific and time-limited objectives) rather than what services they are delivering. Generating these objectives makes it easier for managers to go on to answer the core impact evaluation questions

- "How can we tell if we are making a difference to our users?" or "What do we want to be judged on in delivering these objectives?" Answering these questions usually leads the managers into looking for changes in their users and potential users or in their own staff, in the areas of:

- behaviour (doing things differently)

- competence (doing things better)

- levels of knowledge

- attitudes (e.g. confidence; valuing librarians!)

Once the desired changes are identified, it is relatively easy for managers to think about targets (how much change they anticipate) and to begin to consider how to gather the evidence of change.

\section{The Impact Implementation process is} envisaged as a series of annual cycles, each focussed on a different area of potential impact and with different universities participating at each stage. However, an effort will be made to keep participants involved after completing 'their' cycle, via the project e-discussion group, so that other people can benefit from their experience.

\section{Recruiting participants}

An invitation to participate in the programme was issued early in 2003, emphasising that potential participant universities should be in a position to identify a senior library service manager to lead their work, send participants to the workshops, and commit to evidencegathering between the events. Nine universities in England and one in Scotland ${ }^{*}$ were invited to enrol in the first phase of the programme, which focussed on e-learning support and einformation services.
What factors led the participating libraries to get involved with the Programme? When asked what they were seeking to achieve, the teams offered twelve reasons in all, ranging from internal library management concerns (e.g. "managing spiralling demand for induction and information skills training") to establishing the service more strongly within the university ("showing the library has impact on users"), and from broader educational considerations (such as "convincing academics that information skills work should be embedded in the curriculum") to aligning the library with university priorities ("addressing university themes of promoting independent learners and preparing them for the knowledge society").

\section{Phase I of the Initiative}

The launch event (workshop 1) for Phase 1 was held at Charlecote, Warwickshire in July 2003 and was attended by up to three library and academic staff from each of the ten participating universities. This was seen as a vital part of the action research process because if such work is to run smoothly and if the requisite data collected is to be both challenging and useful it is important to provide secure ground for all the participants and their ensuing work. This focus led us to undertake a strong guidance role in this part of Phase 1; for the same reason we feel that it is important to outline this role and the subsequent workshops.

The objectives for this event (again run over 24 hours) were for participants to:

- confirm their chosen theme for their impact implementation work

- understand the impact process model

- develop high quality impact indicators for their chosen theme

- prepare an action plan to implement a process of appropriate impact evidence collection.

The workshop was divided between facilitator input and time for the university teams to work through their issues and to formulate their own objectives, indicators and implementation plan. The programme consisted of a presentation about impact evaluation issues, leading into an 
introduction to the impact evaluation process model and a review of themes (i.e. areas where the university teams were planning to innovate and to evaluate their impact); participants then worked in groups in applying the various stages of the model to their chosen theme (consisting of one or more university teams depending upon the theme chosen, since there was some overlap). Reviews of each stage of the process were carried out by the facilitators with each group (since plenary review sessions are not usually sufficiently specific and focussed to be effective for this type of activity). A short input on research methods (backed up by handouts) was provided early on the second day of the workshop. The event concluded with teams deciding on actions to be taken before the next workshop. (This programme was modified in year 2 to take account of comments from year 1 participants. More input was provided on research methods and university teams were more actively encouraged to work together on common themes.)

During the course of this initial workshop, participants decided to focus on:

- Enhancing the use of resources that are delivered electronically (including collaboration with staff and skills work with users)

- Information literacy work with students

- Information literacy work with academic staff towards its inclusion in the curriculum

- Developing information literacy packages

- Equipping students with the competence, confidence and skills to support independent and lifelong learning

- Information skills and Personal Development Profiles within foundation degrees

- Developing the Library role in supporting partnership students, including collaboration with college staff

- Raising awareness amongst academic staff of appropriate journals in which to publish research.

(There was some overlap of themes across the teams.)

In order to provide a stimulus to action, we asked each university team to prepare a selfaddressed postcard before they left the workshop, detailing what they expected to have achieved two months hence. We then sent these out as reminders at the end of September.

The main role for the facilitators changed during this inter-workshop part of Phase 1, into a primarily advisory role. Over the next five months after the first workshop, the teams began to sort out their initiatives and gather baseline impact evidence. There was some discussion via the JISCMAIL list established for the pilot, backed up by e-mail and phone calls.

Later in Phase 1 we made an active decision to switch into a troubleshooting role to maintain momentum and encourage critical consideration of issues and concerns. The main purpose of workshop 2 was to identify and address problems that had arisen in the programme so far. Each team was asked to prepare a written progress report for the workshop and to highlight any problems encountered.

This workshop, held in Leeds in December 2003 with roughly the same participants, was a one-day event. This time the objectives were for participants to:

- review progress in evidence-gathering and related activities across the ten Projects within the Initiative

- address specific issues and problems arising so far

- consider how best to engage the support of stakeholders throughout the remainder of the Initiative

The programme consisted of a reminder from the LIRG/Sconul representative about the overall purpose of the programme; group consideration of fundamental questions about the projects so far; answers to these questions by participants/facilitators in a plenary session; a presentation on collecting data; larger group sessions dealing with issues that had emerged so far; and team consideration of next steps.

Workshop 3 was held in London in July 2004. This event was conceived both as a summative workshop and as a means of maintaining the programme momentum. 
This event was seen as important for the overall process in two ways.

- For the teams, this presents a structured opportunity to reflect critically on the outcomes of their work so far, identify issues for further consideration and consider ways in which their enhanced understanding of evaluating impact can be used to further develop their practice

- For the UK university library community, it represents an opportunity to review the initiative so far and begin to explore the scope for achieving commonalities in impact indicators, data collection methods and related benchmarking activities

(We had originally envisaged using this event to launch the next phase of the Programme but in the end we decided to organise a separate launch event for Phase 2, which was held with 12 new participating universities later in July 2004).

In preparation for workshop 3, all ten teams were asked to comment on progress by answering a set of 13 questions (which form the basis of the individual project reports later in this issue).

At this event, a plenary reminder about the aims of the overall programme was followed by an overview of the progress reports; cross-team groups then discussed 'tools and techniques: what works/what we need to do differently'; a further presentation on collecting data was followed by discussion of dissemination and uptake. Cross-team groups then considered one each of four themes: how the evidence collected could be used within (and beyond) the universities concerned; raising the profile of University Libraries; making the case for libraries at the university; and 'convincing your colleagues'. A Round Robin approach was adopted to enable everyone to comment on each theme. Finally, a plenary session considered some larger programme issues: future involvement in the collaborative programme; benchmarking around impact; securing exemplars/best practice; and 'helping and gaining from the next cohort.'

\section{Has the process worked (so far)?}

We have already described the facilitators' main role at the outset as a guidance function - but was this appropriate? Participants generally found the first workshop helpful in engaging with the issues around impact evaluation. Teams were asked to comment four months after the event and a typical summary was:

"Thought that the presenters did very well on quite a dry topic and opened my eyes to the importance of impact assessment. The resource pack was easy to follow and well put together."

Two of the teams would have liked to have worked more with participants from other Universities, but this was not practicable, given the need to ensure that each team had identified its own objectives, success criteria, means of gathering evidence and implementation plan in the space of one workshop. There was also a view that more input would have been useful on methods of data collection.

As noted earlier, one team had intended to focus on information skills and Personal Development Profiles within foundation degrees, but "this required a great deal of cross-college cooperation and inter departmental partnership [which] has not been forthcoming, partly due to structural issues which would take a longer lead time to rectify". As a result, they chose to measure the impact of a new online induction tutorial, which they were about to introduce and which was more completely within their control. Another team sought advice on analysing student bibliographies to assess the impact of their information skills training activities. We suggested that, if their training was successful, the bibliographies should show a wider range of information sources, a better balance between different types of sources, a closer relationship between the assignment and its bibliography, and more accurate citation. 


\section{From research methods to managing change}

The list of problems identified by participants in workshop 2 (table 1) was fairly typical of issues raised in 'introduction to research methods' workshops. Participants suggested some solutions; otherwise, our suggested solutions were based on our broad experience of conducting research.

Table 1: Problems reported before the review workshop

[Some solutions suggested at event two are shown in italics.]

- Strategic/managerial problems:

- conflicting timescales in relation to collecting evidence of impact - project $\mathrm{v}$ service - important to be clear about different evidence-gathering purposes.

- isolating the library contribution to joint initiatives or overall university efforts - get collaborators to comment on the usefulness of the library contribution.

- Cost of commercial software (affecting the thrust to digitise as well as access to einformation) - is there scope for consortia purchasing?

- Research design issues:

- Devising questionnaires to test the skills you want to test.

- Length of questionnaires $\mathrm{v}$ acceptable respondent time - if too many questions consider other methods.

- Screening out library/academic jargon - importance of piloting evidence-gathering instruments with people in the target group.

- Comparative citation levels - getting at previous years; making comparisons when new or revised modules are produced - we have to start somewhere!

\section{- Practical research issues:}

- Getting the picture of academic/researcher publishing behaviour (overcoming the tendency for academics/researchers to tell you what they should be doing) - ask respondents to choose from vignettes/scenarios based on real practice, then adapt/adjust them to make a closer fit to their own behaviour.

- Student failure to recognise their information literacy limitations - timing is important because new students will not have clear idea of what is expected of them at the beginning of a course of study.

- Do users know where they have been when visiting websites? There was evidence that some users had made more or less regular use of the library website without identifying it as one of their sources - try interviewing students whilst they are searching.

- Dealing with unresponsive/defensive/lying interview respondents - training in research interview technique.

[Note: The three main bullet points were added later as a means of grouping the topics. The topics are as reported prior to and as amplified at the event.] 
Interestingly, when we asked participants to review their progress and problems in small groups a different set of issues emerged, with apparently greater emphasis on managerial, as distinct from research programme planning, concerns, as shown in table 2 . The only problem that re-emerged was how to distinguish the library staff contribution to joint efforts or initiatives (other repetition may have been discouraged by the short presentation based on pre-event feedback that preceded the small group session). This new list, and particularly the items summarised there as strategic/managerial problems, makes it clearer that what has been undertaken is a substantial programme of change.

As a result of this strong emphasis on change, the solutions explored at the event tended to draw upon educational change management theory ${ }^{14}$. In our view, it is vital that anyone facilitating this type of facilitated action research development programme should be able to move comfortably between guiding participants through research methods, troubleshooting in relation to specific practical research techniques and giving more general advice about aspects of managing change.

Table 2: Problems identified at workshop 2

\section{- Strategic/managerial problems:}

- the need to reassure selves that sound research methods/methodologies have been chosen - being able to make arguments and defend choices when reporting to academic colleagues, many of whom specialise in aspects of research

- isolating the library impact/contribution to joint initiatives or overall university efforts

- persuading senior library staff, and others to whom they report, of the need to shift from traditional performance monitoring to collecting evidence of impact

- persuading other library staff of the importance of impact evaluation

- organising appropriate professional development so that library colleagues can help to collect reliable evidence

- understanding current innovations in teaching and learning and how they affect library service provision

- what to prioritize and where to start, given the other competing demands on library management time

口 choosing an appropriate number of objectives (the minimum acceptable)

- securing the resources to do undertake impact work effectively

- Research design issues:

- the representativeness of the evidence gathered (e.g. types and sizes of sample)

- how to collect 'unadulterated' evidence, given the vested interests of those involved

- choosing a timescale and timing that will take account of key features in the academic year

\section{- Practical research issues:}

- getting any feedback from academic staff and timing this for maximum effect

- assembling baseline information about impact so that it is possible to identify progress (or lack of it).

[Note: Again, the three main bullet points were added later as a means of grouping the topics. The topics are as reported at the event.] 
As part of workshop 3 we asked participants (in four cross-team groups) to review the Programme so far and to identify what they had gained from involvement. All four groups identified greater understanding of academic staff and how they work in teaching, learning support and research as a key outcome and three felt that they had raised the profile of the library at their universities. Other responses focussed on greater understanding of impact evaluation, ranging from "more structured approach to assessing outcomes of strategy/ services/ innovation" to "personal development, experimentation and establishment of new procedures." One specific benefit was in developing diagnostic tools ("targeting specific groups of students - allows follow-up testing") and, more generally, one team felt that "the process has driven reassessment of current practice."

Participants also gained some interesting insights from engaging in the evidencegathering process, such as that:

- interviews produce 'fairly instant results' compared with other ways of compiling impact evidence and raise awareness amongst those interviewed

- influencing the university and negotiating committees is harder than doing evaluation!

- It makes sense to concentrate evidence collection on what prove to be the more effective tools; if necessary modifying success criteria accordingly

- Semi-structured interviews are productive but time-consuming to analyse.

Asked before the last event which parts of the process they had found most useful, teams singled out:

- Networking and benchmarking with other institutions/colleagues - 3

- Constructing an impact methodology and testing the impact assessment process - 2

- Pre- and post-intervention evaluation, because it sparked interest in different way of evaluating resources and teaching

- "Workshops have been excellent"

- "Frameworks provided by the workshop facilitators were very useful"
- Management of a team research process in a systematic way - greater knowledge of situation - using information to achieve objectives - presentation skills

- "What I learnt from managing the whole process rather than any of its constituent parts"

- Being able to look at one aspect of service provision in depth

- Requirement to report back has been a driver for change!

- Practitioner-based enquiry is very useful providing opportunity to reflect on practice whilst developing new models of intervention

\section{Lessons learnt}

Turning to the lessons that they had learnt from participating in the Programme, all four groups felt that they could have made more or better use of the other participating teams for advice, support and comparison of experience or findings (one group wanted the organisers to force participants to collaborate!). Two of the groups felt that they had over-reached themselves in setting objectives or in the amounts of evidence gathered and that they should have devoted more time to local planning. One group each felt that they should:

- Involve more library colleagues in local impact work

- Give more consideration to how best to engage academic staff in the projects

- Begin to plan for more sustainability/long term impact work

Participants also identified several issues and challenges to be faced in doing this kind of work, notably that there is never enough time available to do the work, let alone to influence institutional policy, or engage with library staff and academic staff, but that these had to be tackled anyway. Other points made were that:

- to be effective, impact work should build on current initiatives and projects

- finding accurate information on programmes currently delivered is problematic

- it is necessary to get approval from the Student Research and Project Panel or the Ethics Committee 
- large scale analysis of modules is rewarding but not practicable on a regular basis!

Two messages for the Programme organisers (which have been taken on board) are that there should be more emphasis on research methods early on in the process and that the second workshop should focus more on successes so far. Further suggestions for Phase 3 of the Programme are that there should be a preproject preparation/reflection stage before the first workshop and that the whole process should be started earlier in the year to allow more work to be done before the Summer break.

As the final stage in workshop 3 participants produced sets of detailed proposals for taking the process forward by systematically raising the profile of university libraries, making the case for impact evidence in the university, convincing their library colleagues of the need for impact work and engaging academics in the process.

The level of reflective practice illustrated by the participants' contributions before and during the two review workshops is a crucial element in the action research process. Opening up people's assumptions and opinions to public scrutiny and engaging in the sharing of ideas through discussion and the production of reports is one important facet of what distinguishes the action research process from simply good professional practice ${ }^{15}$.

Our own view is that both the reports on progress and the range of problems and issues emerging from the two review workshops provide clear indications of the effectiveness of the process so far.

\section{Conclusions}

There is already enough evidence to show that the Impact Implementation Initiative is working as a process. All of the original participating teams completed Phase 1 and they all reported progress in addressing their own evaluation agendas. Again, all the teams reported that they had moved on from measuring performance to beginning to evaluate impact; most have already identified specific developmental benefits from their involvement in the process. More generally, the facilitated action research model appears to be effective in encouraging change of this sort.

The programme of linked events with interim support appears to be generally appropriate as a means of supporting this model of facilitated action research. A variety of issues and concerns has emerged during Phase 1: the nature of these issues has shifted as the project evolved, with broad research application issues giving way to more specific concerns about technical evidence-gathering and related issues, which in turn were overtaken by more general issues about managing change.

Feedback from the participating teams suggests that they have found the support structure helpful. Experience of the facilitation process makes it very clear that, for the process to be effective, facilitators need to be clear about the nature of the support role at each stage in the process and ready to act accordingly. It follows that anyone facilitating this type of action research-driven development programme should be able to move comfortably between guiding participants through research methods, troubleshooting in relation to specific practical research techniques and giving more general advice about aspects of managing change. 
Facilitating the Impact Implementation Programme

Sharon Markless and David Streatfield

\section{References}

* Birkbeck College; Chester College; Glasgow Caledonian University; Open University; University of Gloucestershire; Leeds Metropolitan University; University of Leeds; University of Northumbria; University of Teesside; University of Warwick

I TREATFIELD, D.R. and MARKLESS, S. Invisible learning? The contribution of school libraries to teaching and learning. Report on ... a research project Library and Information Research Report 98 London: British Library 1994.

2 e.g. HOUSE, E.R.(ed.) New directions in educational evaluation Lewes, E.Sussex: Falmer Press 1986; MURPHY, R. and TORRANCE, H. (eds.) Evaluating education: issues and methods London: Paul Chapman 1987; FITZ-GIBBON, C. T. Monitoring education: indicators, quality and effectiveness London: Cassell 1996.

3 STREATFIELD, D.R. and MARKLESS, S. The effective college library British Library Research and Innovation Report 2I Developing FE Series I (8) London: Further Education Development Agency 1997.

4 MARKLESS, S. and STREATFIELD, D.R. The really effective college library Library and Information Commission Research Report 5I Twickenham, Middx. IMA for the LIC 2000 ISBN: 0-9538432-2-X

5 STREATFIELD, D.R. and others Rediscovering reading: public libraries and the National Year of Reading Library and Information Commission Research Report 30 Twickenham, Middx. IMA for the LIC 2000 ISBN: 0-9538432-0-3

6 STREATFIELD, D.R., MARKLESS, S. and others Best Value and better performance in libraries Library and Information Commission Research Report 52 Twickenham, Middx. IMA for the LIC 2000 ISBN: 09538432-I-I

7 www.informat.org (click on Best Value).

8 STREATFIELD, D.R. and MARKLESS, S. Critical evaluation of the LIC Value and Impact Programme London: Resource 2002 www.mla.gov.uk/documents/ev imperb.pdf

9 ELLIOTT, J. Action research for educational change Buckingham: Open U P 1991, p.6I

I0 See, for example: McKERNAN, J. Curriculum action research London: Kogan Page 1996; McNIFF, J. Teaching as learning: an action research approach London: Routledge 1993;WINTER, R. and MUNNGIDDINGS, C. A handbook for action research in health and social care London: Routledge $200 \mathrm{I}$.
II REASON, P. and BRADBURY, H. Handbook of action research: participative inquiry and practice London: Sage 200 I;WINTER, R. and MUNNGIDDINGS, C. A handbook for action research in health and social care London: Routledge $200 \mathrm{I}$.

12 ELLIOTT, J. op.cit.

13 See, for example: KYRILLIDOU, M. and HEATH, F.M. 'Measuring service quality' Library Trends (Spring 200I) 50 I [Special issue]; BROPHY, P.'Digital Resources in Higher Education: some issues arising from the formative evaluation of a national initiative in the United Kingdom' European J. of Engineering for Information Society Applications (September 2002); USHERWOOD, R.C.'Demonstrating impact through qualitative research' Performance Measurement and Metrics 3 (3) 2002.

14 See, for example: FULLAN, M. G. The new meaning of educational change 3rd ed. New York, USA: Teachers College Press 2001.

15 KEMMIS, S. 'Action research and social movement: a challenge for policy research' Education Policy Analysis Archives I (I) 1993. 